\title{
Article
}

\section{Exploring the views of students on the use of Facebook in university teaching and learning}

\author{
Donlan, Leah
}

Available at http://clok.uclan.ac.uk/5975/

Donlan, Leah ORCID: 0000-0002-1320-2803 (2012) Exploring the views of students on the use of Facebook in university teaching and learning. Journal of Further and Higher Education, - (-). pp. 1-17. ISSN 0309-877X

It is advisable to refer to the publisher's version if you intend to cite from the work. http://dx.doi.org/10.1080/0309877X.2012.726973

For more information about UCLan's research in this area go to http://www.uclan.ac.uk/researchgroups/ and search for <name of research Group>.

For information about Research generally at UCLan please go to http://www.uclan.ac.uk/research/

All outputs in CLoK are protected by Intellectual Property Rights law, including Copyright law. Copyright, IPR and Moral Rights for the works on this site are retained by the individual authors and/or other copyright owners. Terms and conditions for use of this material are defined in the policies page. 


\author{
Dr Leah Donlan* \\ Lecturer in Sports Marketing \\ School of Sport, Tourism and The Outdoors \\ University of Central Lancashire \\ Preston \\ Lancashire \\ PR1 2HE \\ UK
}

Tel: $0044(0) 1772894239$

Email: LDonlan@uclan.ac.uk

*corresponding author 


\begin{abstract}
:
Facebook use among students is almost ubiquitous; however, its use for formal academic purposes remains contested. Through an online survey, monitoring student use of module Facebook pages and focus groups, this study explores students' current academic uses of Facebook and their views on using Facebook within university modules. Students reported using Facebook for academic purposes, notably peer-peer communication around group work and assessment; a use not always conceptualised by students as learning. Focus groups revealed that students are not ready or equipped for the collaborative style of learning envisaged by the tutor and see Facebook as their personal domain, within which they will discuss academic topics where they see a strong relevance and purpose, notably in connection with assessment. Students use Facebook for their own mutually-defined purposes and a change in student mind- and skillsets is required to appropriate the collaborative learning benefits of Facebook in formal educational contexts.
\end{abstract}

\title{
Keywords:
}

Social networking; teaching; higher education; Facebook; collaboration

Word count: 6319 


\section{Exploring the views of students on the use of Facebook in university teaching and learning}

\subsection{Introduction}

The infiltration of social media into our everyday lives has transformed the way in which people communicate, do business and is even beginning to change the way in which higher education institutions teach their students. The new generation of students have been termed 'digital natives' (Prensky, 2001), having grown up with an array of new technologies and as such they expect the use of multiple information media (Aragon, 2007). However, such a view has been more recently criticised for taking an overly-optimistic view of students' technological capabilities (Oblinger and Oblinger, 2005) and generalising across what remains a diverse group of individuals with differing levels of technological interest and experience (Bennett, Maton and Kervin, 2008). As such, this paper contributes to the on-going debate by further exploring both students' use of and views on social networking sites in an educational context.

Of the hundreds of social networking sites available online, Facebook is the most well-known and most widely used, with 955 million monthly active users worldwide by June 2012 (Facebook, 2012) and over 35 million users in the UK by August 2012 (Socialbakers, 2012). Previous studies also suggest the pervasiveness of Facebook use among student populations (Hoyer et al, 2010; Smith and Caruso, 2010; Connell, 2009) and while there has been some exploration of the use of social networking sites in an academic context (Estus, 2010; Madge et al, 2009; Selwyn, 2009), given their prevalence in wider society, there is still much to explore in relation to the use of social networking sites such as Facebook in a higher education academic 
context. Therefore, the purpose of this paper is to explore the views of students at a UK university, regarding the use of Facebook for teaching and learning purposes. Isolated studies have examined students' use of Facebook in the UK (Madge et al, 2009); however much of the research has been based around students in the USA (Gray, Annabell and Kennedy, 2010; Pempek, Yermolayeva and Calvert, 2009). Therefore, there is a need to explore in more detail, the views of UK-based students concerning the use of Facebook in teaching and learning, in order to inform practice in this large and fast-changing market for higher education.

In adopting a mixed, multi-stage methodology, this paper builds on previous studies relating to students and Facebook by exploring not only students' current use of Facebook for teaching and learning, but also examining in detail their views on the use of Facebook in the context of university modules. By encompassing student views and an evaluation of student usage of module Facebook pages, this paper extends our understanding in the area of if and how students would like to use Facebook for teaching and learning purposes and also examines their level of readiness to adopt such technologies in an educational context. As such, the findings have both academic and practical significance to those driving developments in higher education pedagogies, particularly in relation to learning technologies.

In order to offer a comprehensive investigation into the current reality and potential of Facebook use in UK higher education, this paper will explore the following research objectives:

1) To examine how (if at all) students currently use Facebook as part of their learning activities;

2) To explore students' use of and views on Facebook pages for taught degree modules; 
3) To critically examine, through the student voice, the potential for and limitations of using Facebook in a higher education academic context.

\subsection{Literature review}

The use of technology in higher education is not a new phenomenon and many higher education institutions use learning management systems such as Blackboard and eLearn within their teaching and learning activities. One criticism of such learning management systems is that they tend to encourage an instructivist approach to teaching (Salavuo, 2008), while social networking sites allow for greater collaboration between students, in line with the pedagogical paradigm of social constructivism (Huijser, 2008). It is precisely this collaborative potential of social networking technologies (Kelm, 2011) which has led to calls for their adoption in teaching and learning. So-called Web 2.0 technologies, of which social networking sites are an example, mirror what are seen to be good models of learning, encouraging collaborative and active student participation (Maloney, 2007) in the co-creation and co-construction of knowledge

(Gunawardena et al, 2009). As such, social media has been positioned as an apposite tool through which educators can blend formal and informal learning experiences (Hoyer et al, 2010). However, while collaborative forms of learning are seen as desirable and beneficial by educators, there has been some resistance to such approaches by students who are not favourable to peerlearning and collaboration (Mason, 2006).

Hung and Yuen (2010) reported a generally positive reaction among students to the knowledgeand information-sharing benefits of social media for educational purposes, in this case using the 
segregated social networking site Ning. Nonetheless, the authors did acknowledge that there were several students in their study who struggled with this notion of knowledge-sharing, perhaps due to lack of familiarity with the technologies or a sense of unease over what constituted knowledge in a social media environment. There is also some concern reported among academics who feel that the way in which so-called Generation Y students use social networking sites will not easily translate into an educational context (Bull et al, 2008). In particular, issues arise around the legitimacy and value of knowledge and information in social networking environments (Bennett and Maton, 2010), with students viewing social media as very much a social tool (Madge et al, 2009).

Compared with the use of segregated social networks like Ning, a primary concern over the use of Facebook for teaching and learning purposes is that Facebook is often seen by students as a private space (Connell, 2009) for their social activities, which is not to be invaded by lecturers. The blurring of boundaries between education and social activities engendered by the use of Facebook (Schwartz, 2009) presents a significant challenge to educators, particularly when it comes to tutors accepting or initiating friend requests from students (Bongartz et al, 2011). Students are often defensive over their “"me' and 'we' spaces" (Hughes, 2009, 24), which are seen as social spaces, beyond the reach of lecturers (Gray, Annabell and Kennedy, 2010) and which include social networking sites such as Facebook. In a survey by Ophus and Abbitt (2009), privacy was mentioned prominently by students as a reason for not using Facebook for university purposes. Similarly, the use of social media for educational purposes is seen to add to the workload of not only staff but also students, (Schroeder, Minocha and Schneider, 2010) and 
several students report that, given the primarily social function of sites such as Facebook, there would be too many distractions if trying to use Facebook educationally (Conole et al, 2008).

Despite some concerns raised by students in terms of privacy and breaking the boundaries of personal space, there is evidence of students using Facebook in an educational context, notably for student-student communication (Ophus and Abbitt, 2009; Selwyn, 2009). In a study of Turkish university students, Baran (2010) found that over $60 \%$ of students felt that communicating with classmates via a module Facebook group helped to motivate them in their learning. However, the distinction is drawn between tutor-initiated and student-initiated uses of Facebook, with the most successful uses being those which were created by students themselves (Whedon, 2011), while tutor-initiated uses were seen as somewhat fake (Ipsos MORI, 2008). Thus, it appears that students see some benefit in using social networks such as Facebook for certain aspects of peer communication, often focussed around group work (Madge et al, 2009) and assessment (Selwyn, 2009). Notably, however, the use of Facebook for peer-peer educationrelated communication is often not seen by students as constituting 'learning' (Ipsos MORI, 2008).

It has been suggested that educators should observe how students use social media technologies and then implement such uses into an educational context (Kelm, 2011). There is evidence that students are comfortable integrating an element of peer-peer (but not necessarily student-tutor) education-related communication and learning into their use of social networking sites; however as Selwyn (2009) cautions, such education-related uses should perhaps be allowed to continue to be initiated by students, rather than being appropriated by educators in a formal sense. The keys 
to effective learning in social networking environments have been identified by Salavuo (2008) as participation, presence and ownership, with Conole et al (2008) adding that students should have a sense of control. The merging of the social and the professional and the formal and the informal through the use of Facebook by educators in higher education remains a contested topic. It is therefore apposite to further consider, as the present study does, the views of students regarding the use of social networking sites for university work.

\subsection{Methodology}

This study adopts a multi-stage, mixed methodology to: comprehensively uncover students' views on the use of Facebook for teaching and learning purposes; monitor the use of Facebook by students in a module context; and explore students' views more deeply on the use of Facebook in this context and more generally for teaching and learning purposes. Phase one of the research involved an online survey administered to students of sport-related courses in a large UK modern (post 1992) university. The purpose of the online survey was to gather quantitative data on current use of Facebook and students' intentions and interest in using Facebook for teaching and learning purposes. The online survey was designed and administered using SurveyMonkey, with invitations to participate sent to all students (undergraduate and postgraduate) studying sport-related courses, giving a total pool of potential respondents of over 600 students. A total of 112 useable responses were obtained.

Of the 112 respondents to the online survey, $69 \%$ were male and $31 \%$ female, which is indicative of the sports focus of degree courses studied by the students in the sample. Just over three 
quarters $(76 \%)$ of respondents were aged between 18 and 21 , with $96 \%$ being full-time (both undergraduate and postgraduate) students and $7 \%$ being international (non-UK) students. Of the online survey respondents, $97 \%$ of students reported using social networking sites, with Facebook being the most popular site, used by $95 \%$ of these respondents. Using chi-squared tests, no significant difference was found between male and female students in their likelihood of using social networking sites $\left(\chi^{2}=0.455, \mathrm{p}=0.500\right)$. However, previous research has indicated that gender, age and ethnicity impact on the use of particular social networking sites (Hargittai, 2008). Therefore, while it was not the intention of this study to explore the impact of such variables, no claims are made about the generalisability of this sample to other student populations.

While the online survey methodology was adopted to allow researchers to gather responses from a large number of students, the online nature of the research may create a bias towards those students who are more confident and comfortable using technology (Hargittai, 2008). In the context of exploring student views on the use of social networking technologies, this represents a limitation of the research. Similarly, those with a strong interest in the topic (which is likely to be those already using social media) would have been more drawn to completing the survey (Duda and Nobile, 2010), again skewing findings towards a positive reaction from students.

Phase two of the research involved the module tutor setting up Facebook pages for three modules in sports marketing, two at $2^{\text {nd }}$ year undergraduate level and one at postgraduate level. Facebook pages were set up in such a way that students registered on the modules could 'Like' the page, allowing posts on the page to appear in their Facebook News Feed. To overcome potential 
reluctance from students, there was no need for students to become 'friends' with the tutor on Facebook. Accessing materials on the Facebook pages was an optional addition to the module content, with core lecture/seminar materials being posted on the university's virtual learning environment module pages and module communications taking place via university e-mail. The module tutor updated the pages on a weekly basis, posting links to supplementary articles (from commercial and academic sources) relating to the topic of the week's lectures/seminars. Using Facebook Analytics, the number of impressions (i.e. click throughs) for each article was tracked to monitor students' use of the resources. An obvious limitation of monitoring student use of resources in this way is that clicking on the article link does not necessarily mean that students read the articles; therefore the number of impressions may inflate the level of student engagement with the materials. However, where student participation is optional (and thus where students' knowledge in relation to the articles could not be systematically tested in any other way), the number of impressions was the best available proxy for student use.

The final phase of the research used a focus group methodology, with a total of four focus groups undertaken, of which two were with students studying the modules for which the Facebook pages were created (group one $n=5$, group two $n=4$ ) and two were with students not on these modules (group three $n=2$, group four $n=3$ ). The students in focus groups one and two were students of sport, while participants in focus groups three and four came from a wider range of subject disciplines, including arts, sciences and social sciences. The focus groups took place towards the end of the academic year, meaning that students on the modules with the Facebook pages had sufficient experience of the pages in action to be able to comment on their (non) use of the pages. All students in the focus groups were aged between 18 and 21 years of age, and each 
focus group contained both male and female participants. Evidently the small size of some of the focus groups represents a limitation of this research and, as with the online survey, no claims are made as to the generalizability of findings beyond the context of this university. The purpose of the focus groups was to explore the experiences of students in using the module Facebook pages, including views on the design and use of the pages and also to explore in more depth students' view on using Facebook for teaching and learning.

\subsection{Results}

\subsection{Online survey}

Student respondents reported using Facebook for a wide variety of activities including keeping up with what friends are doing (80\%), posting status updates (67\%), live chat (69\%) and arranging events (63\%). In terms of potential academic uses for Facebook, as shown in Table 1, over $80 \%$ of respondents reported being interested or very interested in sending messages to fellow students about university work (88\%), sending messages to lecturers (84\%), discussing work with others (86\%), accessing links/articles related to module content (90\%), posting relevant links/articles (82\%) and receiving updates on changes to times/venues of lectures (87\%). From the online survey, therefore, there was evidence of a willingness among respondents to use Facebook for university purposes. In line with previous studies (Madge et al, 2009), some resistance to using Facebook for university purposes was also noted, with $33 \%$ of respondents saying that there is something which would put them off from using Facebook in such a way. Among the most common reasons given were that Facebook is not as good as other tools for 
university work (13\%), a reluctance to let tutors see their personal pages $(10 \%)$ and that Facebook is something they use in their private life, not for study $(11 \%)$. Open responses to the question also included that students would get easily distracted from study by being on Facebook, a preference for face-to-face interactions and concerns over how seriously material on Facebook is taken in comparison to other channels for academic work. As such, the responses in this study echo many of the concerns raised in previous literature (Bennett and Maton, 2010; Conole et al, 2008; Ipsos MORI, 2008).

[Insert Table 1 about here]

\subsection{Use of Facebook pages}

Across the three module Facebook pages, a total of 35 students liked the page for their respective module. More specifically, for the two undergraduate modules 19 out of 26 students and 11 out of 25 students respectively liked the Facebook pages, while 5 out of 7 students on the postgraduate module liked the Facebook page. Therefore, engagement at the basic level of liking the pages ranged from $73 \%$ to $44 \%$ of students. In contrast, all students registered on the modules accessed the virtual learning environment (to a greater or lesser degree) for their respective modules. Using Facebook Analytics, the use of the pages was tracked and students were found to be regularly accessing them. In total, 68 links were posted by the lecturer over the course of the academic year, with links receiving an average of 82 impressions (clicks). The most viewed article (notably, the first article posted, indicating early enthusiasm among students) achieved 381 impressions, with 18 links in total receiving over 100 impressions. The least 
accessed article attracted only 18 clicks, resulting in a range of 363 . While a click through is no guarantee of the student reading the article, it gives an indication of interest in the articles and hence the interest in receiving academic-related materials via Facebook. The results on the number of impressions suggest that many students were accessing the links more than once. However, while students were accessing the materials, no students commented on any of the links or posted any links themselves. This stands in contradiction to the interactive nature of social media and highlights a lack of participation in two-way communication by students. The effect achieved, with students simply accessing links, could consequently have been achieved through a regular learning management system.

\subsection{Focus groups}

Comparing the results of the online survey with the experiences when using the Facebook pages, there appears to be a mismatch between stated intentions or preferences and the reality of using Facebook for academic purposes. While $82 \%$ of survey respondents indicated an interest in posting links to articles, no participants in the Facebook pages posted any content, resulting in the pages being seen as a one-way means of communication. Possible explanations for this lack of interaction were identified through the focus groups. Tellingly, those students who did access the links and the pages reported doing so out of their own interest, rather than with a view to using them in more formal study situations: 
I think a lot of what [the tutor] puts on there is of interest, if you fancy reading it, whereas perhaps more people would use it if she put stuff on there what was a requirement to read.'

[The tutor has identified] the indicative reading for the week which is what is relevant to what she has taught you anyway. So, you can stick to what's been laid out each week. I don't specifically go on [to the Facebook page] as an additional thing unless I would see that something extra has been posted on that I've got an interest in.'

Brenton (2009) suggests that the reason for the failure of many e-learning initiatives may be an insufficient purpose for the intervention in the first place or a failure to build the online element into the day-to-day teaching and assessment on the module. Thus, in this case, the optional nature of the resources on Facebook, which were additional to recommended reading, perhaps failed to firmly establish their position as teaching and learning aids within the module in the eyes of students. Similarly, the predominantly social role for which students use Facebook (Madge et al, 2009) will condition them to accessing resources on the site related to their interests and students appear to apply the same criteria to study resources posted on Facebook. Consequently, use of such resources is likely to be dependent on individual interests, presenting a challenge to academic staff wanting to encourage wider reading among students. Teaching styles on the courses involved in this study vary between teaching staff; however, students are exposed to a range of pedagogical approaches across all years of study, ranging from the more didactic lecture to online resources such as quizzes and podcasts, and interactive and collaborative group seminar and assessment activities. The students were introduced to the 
Facebook pages in the first lecture of each module and the intended role and purpose of the pages as tools for accessing and sharing articles and asking/responding to questions was outlined. However, students were not given specific guidance on the use of social networking tools for academic purposes. Therefore, while the students were at least somewhat familiar with collaborative learning styles from previous experience at the university, they lacked knowledge and experience in using social media for teaching and learning purposes. This lack of knowledge, as evidenced in the findings presented here and later in the discussion, proved telling and is likely to have contributed to the usage patterns identified in the study.

Linked with the notion of e-learning initiatives being seen as central to the teaching and learning process, focus group attendees also raised a particularly pertinent issue of the quality of resources, which might stem from a lack of information literacy in relation to using social networking sites for academic purposes (Bull et al, 2008). Despite the expressive claims from some commentators about the preferences of current students for electronic media (Aragon, 2007), in the words of one student: 'say you do want to do a bit of extra reading, you go to the books that are recommended.' Therefore, students perhaps do not perceive resources posted on Facebook, albeit on an academic module page, as academic resources per se and thus perhaps do not know how to integrate these into their learning activities. A further concern among students in this area relates to the validity of resources on social networking sites. In the words of one student:

'I think a lot of problems you have with social networking...[are] sorting the wheat from the chaff. [There's] a heck of a lot of nonsense on there that you've just got to sort 
through...If I'm doing university work and doing assignment work then I'll go specifically to known places for materials, rather than perhaps relying on strictly social networking places.'

It appears from this study that, despite their apparent status as digital natives (Prensky, 2001), students do not know innately how to learn in a Facebook environment and lack both an understanding of what constitutes knowledge in such settings and the skills required to adapt their understanding of using social networking sites to an academic context. Consequently, students prefer to use tried and tested sources such as books and journals to feel confident that the resources they are using are appropriate. An understanding of the use of Facebook in a social context, no matter how proficient, appears not to automatically transfer into an understanding of its academic role (Bull et al, 2008). As such, before any potential in such uses of sites like Facebook can be realised, there needs to be a drive to educate students in information literacy as it relates to social networking in academia.

The lack of participation in discussions around the posted articles on the Facebook pages was noted by one respondent:

'I think it's interesting to note that... when I've had a scroll down the Facebook page, there's never any comments put on about any of the reports that she's put on. So it makes you think, "Well, have people read it or have people read it and just not commented on it". 
For the collaborative benefits of social networking sites to be realised, there is a need for a collective buy-in from students. If students are seen to be commenting, then other students are likely to also contribute. However, for such a situation to arise, as discussed above, there might need to be a change to students' collective mind set in terms of using social networking sites as a tool for knowledge creation rather than simply information dissemination. The notion of collaboration is often vaunted as a significant academic benefit of social networking sites (Mason, 2006), but again, their use for this purpose might necessitate a change in how students see knowledge construction. From the focus groups, some reluctance to share resources was identified:

'I wouldn't want to use [the articles posted on Facebook] in my assignments because I'd feel like everyone was looking at them, so I don't want everyone to be coming in with the same...I'll be thinking everyone's putting it in so I'll go find something else...'

'you think, well if I'm searching for it, why should everyone else get it...'

Therefore, again there is a lack of understanding among students of the benefits of collaborative learning which could be achieved through the use of social networking sites. Despite regularly undertaking group assignments (albeit, not via social media), students still see assessment as a zero sum game, rather than seeing the potential learning benefits of collaborative learning. Once again, a need to educate students in the use of social media for teaching and learning is identified as a preliminary step to expecting students to fully engage with learning materials and academic knowledge construction on social networking sites. 
From the focus groups, and supporting the views expressed above from the online survey, it was clear that one of the main purposes for which students wanted Facebook to be used by academics was in providing administrative updates, such as room changes, lecture cancellations or reminders of deadlines. It was felt that for updates such as these, which may be time critical, 'people are more likely to see it on Facebook' than via e-mail, with students reporting a lower frequency of accessing university e-mail compared with Facebook. Rather than as an educational tool, it appears that students see the most useful application of Facebook in an administrative function. Again, then, we see that in a general sense, there is support among students for using Facebook for university purposes, but these purposes might not be what are conceived by academics as falling under the banner of teaching and learning.

In addition to administrative updates, students in the focus groups also identified an interest in using Facebook for assignment support, including being able to post questions for lecturers. This was seen to be a particular benefit in that, unlike with email or other one-to-one communications media, all students could see the questions posed and the tutor's responses. There is an element of contradiction here with the earlier discussed reluctance to share resources, in that students extol the communal virtues of social networking technologies for accessing information given by tutors in relation to assignments, but are resistant to the sharing of materials in order to protect the resources they have found. Again, there is a clear gap emerging between the much vaunted collaborative learning potential of social networking sites (Huijser, 2008) and students' perceptions of how they should be used. Students in the focus groups also identified the 
potential of Facebook for student-student interaction in answering each other's questions relating to assignments:

'Other people's questions could help you because they could ask a question and you'd be like, oh I never thought of doing that in the work. That can help you with yours.'

'if you put it on [Facebook], you can see what other people have asked, because when I do work at night, you get stuck. You have to send emails. Sometimes you can't carry on until they've answered your question. So, you might be able to get it back quicker if you do it on Facebook.'

The difference between collaboration in this sense and simply sharing resources is that students see a strong purpose and relevance for this type of application of Facebook pages. The students in the focus group displayed a strong focus on assignments, privileging these over a more holistic approach to learning. Therefore, there is a greater willingness to collaborate using social networking sites when students perceive the potential for mutual benefit (i.e. not only can their questions/answers benefit others but the questions/answers of others can also benefit them) rather than in the more general sense of sharing resources. There was also some enthusiasm among students in the focus group for contacting tutors via Facebook, but again, this was couched in a context of asking questions about assignments. As such, the students appear to see Facebook as a convenient means of communication about academic issues, which may result in learning. 
In terms of current use of Facebook for academic purposes, students in the focus groups reported posting assignment-related status updates, which fellow students will then comment on, creating a discussion around the assignment. Tellingly, one student prefaces his response with 'I've not really used Facebook for university purposes, ' then goes on to talk about using Facebook to discuss assignments. As such, there is some evidence of collaborative learning taking place, but this learning is very assignment-focussed and strategic and is perhaps not perceived by students as part of their learning. As with the point raised above relating to waiting for staff to reply to emails, the need for immediacy of response among students is facilitated by the ubiquitous nature of Facebook among the student sample:

'because everyone's got each other on Facebook...if we're stuck with something, then everyone's always in the library, always using Facebook to ask people what book they've used [and] stuff...'

Similarly, several students reported creating closed Facebook groups for group assignments, so that they could share ideas and documents, without the need for all students to be physically present on campus:

'we use Facebook, as like a communication tool, like we're doing a lot of group assignments so we're all in the same messages and stuff and you can constantly communicate with each other like send links out, send photos, all the research we find. So, we all get it and all share it rather than texting someone or trying to email so we are all included in the same thing.' 
While there was little interaction from students on the module Facebook pages created in this study, there is evidence that students are using Facebook for academic purposes; however the key point here is that they are student-initiated, when the students feel there is a need for such interactions. Therefore, where students do want to use social networking sites for academic purposes, these purposes do not necessarily mesh with the views of academics in terms of how they would like to see social networking sites being used.

The key difference between the reluctance to use Facebook for academic work such as accessing and sharing resources and the willingness of students to ask questions of tutors and discuss work with each other on Facebook is one of ownership. There is a definite sense of Facebook being the students' domain and an environment in which they feel comfortable talking to each other on a social level. A concern raised in the literature is that of privacy (Madge et al, 2009) and a general consensus was reached among focus group participants, which was succinctly articulated by one student: 'I don't think I'd want tutors as a friend on Facebook really, I'd send a message, but I wouldn't want them as a friend.'

Several students also reported that they actively avoid Facebook when studying because 'on Facebook there is so much to click on, you can be easily diverted,' and 'there's loads of distractions when you go on Facebook.' Issues of study-life balance were also raised in this context, with students overwhelmingly seeing Facebook as 'definitely just a social tool,' and resenting any perceived intrusion from academic staff into that domain. 
The current uses made by students of Facebook were initiated by them, the students, and as such they are using Facebook academically on their terms. When tutors drive the use of Facebook, as in this study, the vital qualities of ownership and purpose are missing, meaning that such interventions are more likely to fail. The issue, as articulated by one focus group participant, becomes one of not only ownership and sense of purpose, but also has deeper links to students' perceptions of Facebook and its role:

'if you're on Facebook for you know normal social purposes then you're not really going to be in the frame of mind to sit down to an academic study that's been posted on there or a business report or whatever. I don't know Facebook's maybe, got to grow in people's mind to change you know through time for that to happen and I don't know [if it will].'

\subsection{Conclusion}

This study has explored students' views on the use of Facebook in an academic context, finding, as with several previous studies, that the picture is far from clear and there is still a considerable amount of diversity among students in terms of existing adoption and willingness to use Facebook for teaching and learning purposes. Survey findings indicated an interest among students in using Facebook for a range of teaching and learning purposes, including accessing and posting links, discussing work with others and tutorials with lecturers. However, the Facebook pages created for three modules in sports marketing failed to attract any comments or posts from students, suggesting a mismatch between stated potential interest and actual behaviour. Through focus group discussions, several drawbacks to the approach adopted were 
identified. In this case, in setting up the pages without prior consultation with students, the tutor imposed on students her idea of how Facebook should be employed; a conceptualisation of learning for which it emerged the students were not ready. Any future use of Facebook for teaching and learning purposes would thus require a change in mind set among students and would likely necessitate a process of re-education to present to students the benefits of collaborative approaches to learning and knowledge creation in such environments.

While several students reported using Facebook to discuss university work, particularly in the context of group assignments, there was some resistance to notions of collaboration and collectivism in terms of sharing resources, with students feeling protective over the resources they had identified. Equally, in line with previous studies, support for using Facebook as part of university life was not universal, with several students raising issues of the potential for distraction on Facebook and the wish to keep study and personal lives separate. The overriding focus of the students' current use of Facebook relates to assignments and it is in this context that students have set up Facebook groups or message threads. The key difference between how students use Facebook for academic purposes and the way in which Facebook pages were created by the tutor lies in the perceived relevance of the uses. Where students perceive that Facebook can serve their needs, particularly for peer-peer interaction around assignments, there was evidence of a willingness to use Facebook in an academic context. Thus, it appears that currently, certain students are happy with using Facebook for academic purposes when it is on their terms, where its use is student-directed and where they see a defined purpose and relevance. 
These findings will have relevance to university teaching staff seeking to employ social networking sites within their teaching. By not only reporting students' views on how and for what purpose they would like to use Facebook in an academic context, but also examining student reactions to the actual use of Facebook in a teaching and learning context, this study builds on our previous understanding of the complexity of the reality facing lecturers considering the adoption of social networking technologies. As with many previous studies exploring social networking sites for teaching and learning purposes, there is no overwhelming consensus among students regarding their use. Evidence from this study suggests that if Facebook is to be a valuable tool for teaching and learning, there is a need to find out how to foster student ownership, participation and engagement with the designated module pages. Equally, it is important to educate students about how social media can be used in a teaching and learning context; tutors must not assume that students' understanding of its use in a social context transfers automatically to an academic setting. It may be that practically, Facebook is not the right environment for all of the different types of collaborative learning opportunities to which it lends itself theoretically. Facebook was conceived as a social tool for students and while their uses of the site have grown and diversified, they use it very much on their terms and for their own mutually-defined purposes. To attempt to change such practices and impose their own frames of reference with regards to its purpose may ultimately prove to be the downfall of academics' attempts to integrate Facebook into their teaching and learning.

\subsection{Limitations and areas for future research}


While adopting a mixed methodology incorporating both qualitative and quantitative data and exploring stated student intentions and reality, a limitation of this study is that it explored the views of students at one period in time. As the pace of change with technology is so rapid and as its use becomes more ubiquitous at lower levels of education, we may see a shift in attitudes and preferences among learners in higher education. Therefore a pertinent avenue of future research is to replicate such studies over time, applying a longitudinal approach to explore whether students' conceptualisations of relevant teaching and learning activities on Facebook evolve. The findings from this study imply that students currently remain to be convinced by the use of Facebook for formal teaching and learning purposes; however, we may be on the cusp of a significant change as future generations of learners enter higher education with greater prior exposure to collectivist notions of learning via social media. As such, this remains a constantly evolving area and one worthy of further investigation to allow us to more fully understand both the potential of such technologies and the practicalities of their adoption.

\subsection{References}

Aragon, J. 2007. Technologies and pedagogy: How YouTubing, social networking, and other web sources complement the classroom, Feminist Collections 28, no. 4: 45

Baran, B. 2010. Facebook as a formal instructional environment, British Journal of Educational Technology 41, no. 6: E146-E149

Bennett, S., and K. Maton. 2010. Beyond the 'digital natives' debate: Towards a more nuanced understanding of students' technology experiences. Journal of Computer Assisted Learning 26, no. 5: $321-31$

Bennett, S., K. Maton, K., and L. Kervin. 2008. The 'digital natives' debate: A critical review of the evidence. British Journal of Educational Technology 39, no. 5: 775-86 
Bongartz, J., C. Vang, D. Havrda, M. Fravel, D. McDanel, and K.B. Farris. 2011. Student Pharmacist, Pharmacy Resident, and Graduate Student Perceptions of Social Interactions With Faculty Members. American Journal of Pharmaceutical Education 75, no. 9: article 180

Brenton, S. 2009. E-learning - an introduction. In A Handbook for Teaching and Learning in Higher Education $3^{\text {rd }}$ edition ed. H. Fry, S. Ketteridge and S. Marshall. 85-98. Abingdon: Routledge

Bull, G., A. Thompson, M. Searson, J. Garofalo, J. Park, C. Young, and J. Lee. 2008. Connecting informal and formal learning: Experiences in the age of participatory media. Contemporary Issues in Technology and Teacher Education 8, no. 2: 100-7

Connell, R.S. 2009. Academic Libraries, Facebook and MySpace, and Student Outreach: A Survey of Student Opinion, Libraries and the Academy 9(1) 25-36

Conole, G., M. de Laat, T. Dillon, and J. Darby. 2008. 'Disruptive technologies', 'pedagogical innovation': What's new. Findings from an in-depth study of students' use and perception of technology. Computers \& Education 50, no. 2: 511-24

Duda, M.D. and J.L. Nobile. 2010. The fallacy of online surveys: No data are better than bad data, Human Dimensions of Wildlife 15, no. 1: 55-64

Estus, E.L. 2010. Using Facebook Within a Geriatric Pharmacotherapy Course. American Journal of Pharmaceutical Education 74, no. 8: article 145

Facebook. 2012. Fact Sheet. http://newsroom.fb.com/content/default.aspx?NewsAreaId=22

Gray, K., L. Annabell, and G. Kennedy. 2010. Medical students' use of Facebook to support learning: Insights from four case studies. Medical Teacher 32, no. 12: 971-6

Gunawardena, C.N., M.B. Hermans, D. Sanchez, C. Richmond, M. Bohley, and R. Tuttle. 2009. A theoretical framework for building online communities of practice with social networking tools. Educational Media International 46, no. 1: 3-16

Hargittai, E. 2008. Whose space? Differences among users and non-users of social network sites. Journal of Computer-Mediated Communication 13, no. 1: 276-97

Hoyer, J., G. Thompson, L. LeBleu, and T. Collard. 2010. An Analytical Statistical Assessment of the use of Social Media Among Marketing and Public Relations Students in the UK, France and USA. Paper presented at Academy of Marketing Conference, July 2010, Coventry, UK

Hughes, A. 2009. Higher education in a Web 2.0 world: Report of an independent committee of inquiry into the impact on higher education of students' widespread use of Web 2.0 technologies. http://www.jisc.ac.uk/publications/generalpublications/2009/heweb2.aspx 
Huijser, H. 2008. Exploring the Educational Potential of Social Networking Sites: The Fine Line between Exploiting Opportunities and Unwelcome Imposition. Studies in Learning, Evaluation Innovation and Development 5, no. 3: 45-54

Hung, H-T. and S.C-Y. Yuen. 2010. Educational use of social networking technology in higher education. Teaching in Higher Education 15, no. 6: 703-14

Ipsos MORI. 2008. Great Expectations of ICT. How Higher Education Institutions are measuring up. London: Ipsos MORI

Kelm, O.R. 2011. Social media: It's what students do. Business Communication Quarterly 74 (4), 505-520

Mack, D. M., A. Behler, B. Roberts, and E. Rimland. 2007. Reaching students with Facebook: Data and best practices. Electronic Journal of Academic and Special Librarianship, 8, no. 2. http://southernlibrarianship.icaap.org/content/v08n02/mack_d01.html_(accessed April 25, 2012)

Madge, C., J. Meek, J. Wellens, and T. Hooley. 2009. Facebook, social integration and informal learning at university: 'It is more for socialising and talking to friends about work than for actually doing work'. Learning, Media and Technology 34, no. 2: 141-55

Maloney, E.J. 2007. What Web 2.0 can teach us about learning, Chronicle of Higher Education 53, no. 18: B26

Mason, R. 2006. Learning technologies for adult continuing education. Studies in Continuing Education 28, no. 2: 121-33

Oblinger, D. and J. Oblinger. 2005. Is It Age or IT: First Steps Toward Understanding the Net Generation. In Educating the Net Generation ed. D.G. Oblinger and J.L. Oblinger. http://net.educause.edu/ir/library/pdf/pub7101b.pdf

Ophus, J.D. and J.T. Abbitt. 2009. Exploring the potential perceptions of social networking systems in university courses. Journal of Online Learning and Teaching 5, no. 4. http://jolt.merlot.org/vol5no4/ophus_1209.htm (accessed April 19, 2012)

Pempek, T.A., Y.A. Yermolayeva, and S.L. Calvert. 2009. College students' social networking experiences on Facebook. Journal of Applied Developmental Psychology 30, no. 3: 227-38

Phillips, T.M. 2009. Does social desirability bias distort results on the Ego Identity Process Questionnaire or the Identity Style Inventory? Identity: An International Journal of Theory and Research 9, no. 1: 87-94

Prensky, M. 2001. Digital natives, digital immigrants, On The Horizon 9, no. 5: 1-6

Salavuo, M. 2008. Social media as an opportunity for pedagogical change in music education, Journal of Music, Technology and Education, 1, no. 2/3: 121-36 
Schroeder, A., A. Minocha, and C. Schneider. 2010. The strengths, weaknesses, opportunities and threats of using social software in higher and further education teaching and learning. Journal of Computer Assisted Learning 26, no. 3: 159-74

Schwartz, H.L. 2009. Facebook: the new classroom commons? Chronicle of Higher Education 56, no. 6: B12-B13

Selwyn, N. 2009. Faceworking: exploring students' education-related use of Facebook, Learning, Media and Technology 34, no. 2: 157-74

Smith, S.D. and J.B. Caruso. 2010. The ECAR study of undergraduate students and information technology, 2010. http://net.educause.edu/ir/library/pdf/EKF/EKF1006.pdf

Socialbakers. 2012. Europe Facebook Statistics. Available at: http://www.socialbakers.com/countries/continent-detail/europe

Whedon, S.W. 2011. Read our manifestoes: Student-motivated Facebook use. Feminist Collections 32, no. 1: 26 